\title{
UMA EXPERIÊNCIA VIVIDA POR UMA CUIDADORA, COMO PACIENTE, UTILIZANDO A NARRATIVA LITERÁRIA
}

\author{
Vera Regina Waldow ${ }^{1}$
}

\begin{abstract}
${ }^{1}$ Doutora em Educação em Enfermagem. Professora aposentada da Escola de Enfermagem da Universidade Federal do Rio Grande do Sul. Rio Grande do Sul, Brasil. E-mail: waldowvr@portoweb.com.br
\end{abstract}

\begin{abstract}
RESUMO: Trata-se do relato de uma experiência vivida por uma cuidadora, como paciente, em uma capital do Sul do Brasil. O evento narrado abrangeu o período de dezembro de 2009 a abril de 2010. Objetivou-se desvelar comportamentos e atitudes de cuidado ou humanização por parte de profissionais de saúde (cuidadores), assim como de pessoas leigas. Utilizou-se a narrativa literária como estratégia metodológica, e a análise interpretativa evidenciou, por parte dos cuidadores, atitudes e comportamentos considerados como de não-cuidado (desinteresse, indiferença e até grosseria), enquanto que, por parte dos leigos, observou-se interesse, gentileza, solidariedade, preocupação, que levaram ao seguinte questionamento: “quem cuida, afinal?" A experiência mostra que, apesar da implementação da política de humanização, profissionais de saúde não conseguem expressar sensibilidade, limitando-se em desenvolver ações de ordem técnica, ou seja, dando prioridade ao enfoque curativo, em detrimento de uma atenção centrada no paciente.
\end{abstract}

DESCRITORES: Humanização da assistência. Assistência centrada no paciente. Narração. Cuidados de enfermagem.

\section{A LIVED EXPERIENCE OF A CAREGIVER AS A PATIENT USING LITERARY NARRATIVE}

\begin{abstract}
This text is about an event experienced by a caregiver as a patient in a southern Brazilian city. The time period comprehended by the narrative was December, 2009 to April, 2010. It aimed to show behaviors and attitudes of care or humanization by health professionals (caregivers) as well as by lay people. The literary narrative was used as a methodological strategy and resulting interpretative analysis evidenced attitudes and behaviors from the caregivers considered to be non-caring (lack of interest, indifference, and even rudeness) while interest, kindness, solidarity, and preoccupation was observed from the lay people's part, prompting the question, "Who does care, anyway?" This experience shows that, despite the implementation of humanization policies, health professionals do not succeed in expressing sensibility, limiting themselves to develop technical actions, in other words, giving priority to a curative focus in detriment of patient-centered care.
\end{abstract}

DESCRIPTORS: Humanization. Patient-centered care. Narrative. Nursing care.

\section{UNA EXPERIENCIA VIVIDA POR UNA CUIDADORA COMO PACIENTE A TRAVÉS DE LA NARRACIÓN LITERARIA}

\begin{abstract}
RESUMEN: Este es el relato de una experiencia vivida por una cuidadora como paciente, en una capital del sur de Brasil. El evento narrado comprendió el período de diciembre de 2009 hasta abril de 2010. Este estudio tuvo como objetivo descubrir las actitudes y los comportamientos de cuidado o de la humanización de los profesionales de la salud (los cuidadores), así como de personas laicas. Se utilizó la narración literaria como una estrategia metodológica, y el análisis interpretativo mostró actitudes y comportamientos, por parte de los cuidadores, considerados como no asistenciales (desinterés, indiferencia, y a veces, mala educación), mientras que por parte de las personas laicas se observó interés, amabilidad, solidaridad y preocupación, o que condujo a la pregunta: “¿Quién es que cuida, a fin de cuentas?" La experiencia muestra que, a pesar de la implementación de una política de humanización, los profesionales de salud no consiguen expresar sensibilidad, limitándose a desarrollar acciones de orden técnica, o sea, dan prioridad al enfoque curativo en detrimento de una atención centrada en el paciente.
\end{abstract}

DESCRIPTORES: Humanización de la asistencia. Asistencia centrada en el paciente. Narrativa. Cuidados de enfermería. 


\section{INTRODUÇÃO}

O presente artigo tem como objetivo desvelar comportamentos e atitudes consideradas dentro do que se caracteriza como humanização ou cuidado. Utiliza a narrativa literária como recurso para relatar uma experiência vivida por uma cuidadora, na condição de paciente, em diversos momentos configurados em cenários. Portanto, trata-se de uma narrativa personalizada ${ }^{1}$, ou seja, enfoca a subjetividade do próprio narrador, como protagonista, que sofre um acidente de trânsito, e como se dão as relações com pessoas leigas e equipe de saúde em diferentes circunstâncias e diferentes serviços de saúde.

O cuidado é considerado um fenômeno existencial, fazendo parte do ser, e como condição que confere humanidade a esse ser. Além disso, caracteriza-se por só ocorrer em relação a outro ser, ou seja, revela-se na coexistência e, por fim, por ser contextual, significando com isso que varia sua forma de expressão, conforme o meio em que ocorre. ${ }^{2}$ A humanização, portanto, uma consequência inevitável do ato de cuidar, envolve "[...] considerar a essência do ser humano, o respeito à individualidade e às diferenças profissionais bem como a necessidade da construção de um espaço concreto nas instituições de saúde, o qual legitima o aspecto humano de todas as pessoas envolvidas na assistência". 3:428

Os termos cuidado e humanização não têm sido alvo de questionamento. Por vezes, são tratados como sinônimos e, por outras, como apresentando diferenciações. Contudo, parece claro, segundo o escrito anteriormente, que é o cuidado que permite a condição de humanidade ao ser. Como não existe um consenso, optou-se por utilizar os dois termos, de forma a contentar os adeptos de um ou de outro termo. ${ }^{4}$

\section{MÉTODO}

O método utilizado para o relato da experiência baseia-se na narrativa literária. ${ }^{5} \mathrm{~A}$ experiência, em seus diferentes momentos, foi organizada em cenários, descrevendo os elementos figurativos, temporais e espaciais.

Opina um autor que "uma das maneiras de aproximar-se à noção de relato ou narrativa - uma das mais tradicionais também - é considerá-la como uma forma, entre outras, de comportamento humano: um comportamento mimético (imitativo) e representativo, a serviço da comunicação de mensagens entre seres humanos". 5:10
A narrativa (ou relato) consiste em contar uma história. A narratividade pode ser abordada com base em concepções semióticas e se enquadra também sob a perspectiva de discurso, podendo apresentar dois níveis: a narrativa que abrange o que é narrado e o discurso stricto sensu, que abrange o modo de contar o que é narrado. ${ }^{5}$

O sentido implica em entendimento, no significado que contém a narrativa, ou também, em intencionalidade e finalidade. $\mathrm{Na}$ presente narrativa, o sentido ou significado é buscado na articulação entre o que é expresso e o que é abstraído do conteúdo. Portanto, a narrativa visa desvelar o cuidado ou a humanização que os protagonistas expressam em suas atitudes e comportamentos (segundo a visão da narradora) e avaliar (também por parte da narradora) esses dois conceitos, na forma como puderam ser transcodificados.

A narrativa, neste texto, é analisada sob a forma interpretativa ${ }^{6}$, ou seja, faz a articulação do evento com o sentido. Desvela os modos de ser dos protagonistas - cuidadores leigos e profissionais, a partir de suas expressões no mundo, no que tange às atitudes e comportamentos humanizantes ou de cuidado.

Um estudo bastante elucidativo da narrativa na enfermagem consiste em um estudo utilizando a fenomenologia interpretativa realizada em duas etapas: a primeira publicada em $1984,{ }^{7}$ e a segunda, em 1996. ${ }^{8}$ Os estudos apresentam narrativas de enfermeiras de unidades de tratamento intensivo e, por meio delas, as autoras conseguem desvelar e compreender como as enfermeiras utilizam seu conhecimento na prática. Ou seja, através das narrativas, ficam claros o sentido e as possibilidades para o agir em determinadas situações da prática clínica. Julgamento clínico, intuição, conhecimento, sensibilidade e tomada de decisão estão entre alguns dos elementos importantes extraídos na interpretação das narrativas.

A narrativa da experiência vivenciada foi organizada em sete cenários, a saber - "O acidente", "O tratamento", "Aguardando a alta", "A cirurgia, o pós-operatório e o cuidado", "A volta para casa", "A relação médico-paciente," e "A recuperação". Posteriormente, alguns elementos de cada cenário são destacados, focando as atitudes e comportamentos de cuidado ou humanização.

\section{Narrando os cenários}

A seguir, apresenta-se a experiência vivida pela autora do presente trabalho, narrada 
cronologicamente, conforme ocorreram os fatos expostos nos sete cenários. Os cenários ocorreram em uma cidade do Sul do Brasil e, em ordem, o acidente ocorreu em um semáforo de uma rua de localização mais ou menos central; a vítima foi transportada para o Pronto-Socorro Municipal da cidade; e a cirurgia e a hospitalização, bem como a primeira consulta pós-operatória, deram-se em um dos hospitais universitários da cidade. As demais consultas ocorreram em uma Clínica de Ortopedia e Traumatologia e o período transcorrido desde o acidente (16/12/2009) até o final da narrativa, com a paciente ainda em recuperação, foi abril de 2010.

\section{Cenário 1 - O acidente}

Estávamos a uma semana do Natal. Caminhava tranquilamente em direção à minha terapia. Apesar do tráfego intenso, percebi que a rua, que deveria atravessar, encontrava-se totalmente vazia. Ao chegar perto da calçada, percebi que o sinal da transversal abriu, e que um carro estava manobrando em minha direção. Não podia voltar atrás e pareceu-me óbvio que o motorista havia me visto, não sendo necessário apressar o passo ou correr. Repentinamente, o motorista avançou. Surpresa, ainda coloquei a mão no capô e gritei - "Para!". Senti um baque, fui atirada ao chão, tentei erguer-me, porém só consegui ficar sentada, apoiando as mãos e com a perna esquerda em abdução, a partir do joelho. Aturdida, pensava e murmurava: -"Não, isto não pode estar acontecendo! Não é possível!" Imediatamente, pessoas vieram acudir-me, indagando como eu estava, onde havia batido, o que podia mover, e assim por diante. Falei: - "Não consigo me mexer da cintura para baixo!" O motorista desceu e disse: - "Eu não lhe vi, mas não foi nada, vou levá-la para casa", no que foi contestado pelas pessoas. Trouxeram alguns papelões para colocar sob as minhas mãos - "Para não queimar, pois o asfalto está muito quente". Outra pessoa trouxe uma caixa (de papelão) para apoiar minhas costas - "Enquanto aguarda socorro, para ficar mais confortável". Todas as medidas tomadas, certificando-se de que não me prejudicariam. Uma das pessoas, que ficou ao meu lado durante esse tempo, uma enfermeira, deu algumas coordenadas. Ao longe, comecei a ouvir a sirene de uma ambulância. - "Ah estão chegando!" E eu, dizendo a mim mesma: - "Não, isto não pode ser para mim, não é possível! É um pesadelo!" Feitas as perguntas de praxe para checar consciência e indagar o que podia mover, verificando onde apresentava lesões, colocaram-me em uma maca, para dentro da ambulância. Dentro, mais algumas perguntas, verificação de pulso; a pressão não foi possível medir, pois estavam sem o aparelho. $\mathrm{O}$ jovem condutor do carro, que havia me atropelado, estava muito atrapalhado e, sempre ao celular, ofereceu-se para contatar algum familiar, porém recusei, pois sabia que naquele horário não seria possível encontrar alguém. Apesar de não ter sucesso em contatar socorro e polícia, o que foi providenciado pelas pessoas que me socorreram, $\mathrm{o}$ rapaz falou: - "Não é nada, vou lhe dar assistência, tenho seguro contra terceiros, não se preocupe!" A Brigada Militar solicitou meus documentos e falaram que fariam contato, mais tarde, em minha residência. A seguir, a ambulância saiu em direção ao Serviço de Pronto Socorro para a unidade de Traumatologia.

\section{Cenário 2 - O tratamento}

A maca percorreu alguns corredores e tomou o elevador, em direção à Unidade de Emergência em Traumatologia. É estranha a visão que se tem da maca, na horizontal, e estando na condição de paciente. Percebi que, apesar da fila de pacientes em espera, deveria haver regras de atendimento, pois "furei" a fila. Uma médica fez algumas perguntas quanto a minha mobilidade e dor e, depois de medicada, fui levada ao RX. Lá aguardei junto com outros pacientes e uma menina que também "furou" a fila, pois parecia ter sido vítima de um tiro na face. Retornando do RX, a médica falou: “É, tem um 'quebradinho' aí (referindo-se à região do joelho), mas a bacia não tem fratura". A conduta foi tala gessada e, após, ao liberar-me, falou para que procurasse um Serviço de Ortopedia e Traumatologia o mais rápido possível. No laudo constatei o diagnóstico: "fratura de plateau tibial com afundamento" e uma indicação de tratamento cirúrgico. Não dei muita atenção, achei exagero, pois pensava (na verdade era o que eu queria acreditar) ser uma fratura simples que, depois de ficar com gesso por algum tempo, faria fisioterapia e estaria apta a retomar minhas atividades, as quais incluíam caminhadas diárias. Antes de colocarem a tala gessada, pedi a comadre, pedido que pareceu um pouco inusitado, pela expressão facial da técnica de enfermagem.

\section{Cenário 3 - Aguardando a alta}

Mais tarde, aguardando na maca no corredor para secar o gesso e aguardar a alta, pedi novamente a comadre. Estava constrangida, mas ao mesmo 
tempo preocupada. Não sabia se pelo susto ou se pelo traumatismo na bacia, eu estava necessitando urinar com tanta frequência. A técnica de enfermagem pareceu ignorar meu segundo pedido, até que, passado mais algum tempo, falei: - "Desculpe a insistência, mas eu realmente preciso urinar". Não obtendo resposta, pedi a outro funcionário que me fizesse o favor de trazer uma comadre e que eu mesma poderia colocá-la. Fui atendida, porém não consegui colocá-la, pela dor que provocava ao mexer a bacia. Liberada, precisava aguardar um familiar ou pessoa responsável. O rapaz, que havia me atropelado, não se encontrava no local; percebi que havia me abandonado! Insistiam que eu deveria ter alguém. Dei o telefone de uma amiga que, supus, poderia contatar alguém da minha família. Fariam o "favor" de ligar, mas não era permitido, só em casos de extrema necessidade. O funcionário voltou, dizendo que o número não atendia. Como o tempo estava passando e eu continuava sem ter ninguém, o funcionário chamou a enfermeira responsável. Ao chegar, eu a ouvi dizer que era um caso para o Serviço Social. Ao pegar minha ficha, reconheceu-me como enfermeira e prontificou-se a tentar telefonar para minha irmã (naquele horário, estava segura que a encontraria em casa). Levou-me pessoalmente para a saída de pacientes. Foi muito amável, fazendo-me companhia até chegar o táxi. A enfermeira solicitou ajuda de outras duas funcionárias que estavam pelo local e assim consegui entrar no táxi. O motorista, uma pessoa muito simpática e atenciosa, fez várias recomendações, fruto de "sua experiência" em transladar pacientes, pois seu ponto original era em outro hospital. Ao chegarmos à minha casa, dispôs-se, prontamente, a me auxiliar, apoiando-me para chegar até a porta. O problema era a escada, estava com dificuldade de apoiar a outra perna, em função do traumatismo na bacia, e a tala pesava muito, pois ainda estava molhada. Sem alternativa, e apesar de minha recusa e constrangimento, ele carregou-me no colo até o hall, subindo as escadas e colocando-me no sofá. Foi embora, não antes de algumas recomendações. Não tinha como levantar e locomover-me e me ocorreu usar a cadeira do computador, com rodinhas. Foi minha salvação; conseguia mover a cadeira, empurrando-a com a perna direita, mesmo com o quadril dolorido. Estava proibida de apoiar a perna com o gesso. No dia seguinte, aluguei um par de muletas e, dali em diante, consegui andar com a ajuda das mesmas. Na Clínica de Ortopedia e Traumatologia, foi constatado ser caso para cirurgia, com certa urgência. A clínica era formada por vários especialistas: ombro e cotovelo, joelho, tornozelo e pé, quadril, e assim por diante. Foi com dificuldade que entrei e sentei no minúsculo consultório, na parte inferior da clínica. Os demais estavam localizados no andar superior.

\section{Cenário 4 - A cirurgia, o pós-operatório e o cuidado}

Agora, estava sob os cuidados do Dr. X, especialista em joelhos. Marcou exames laboratoriais, uma tomografia e a cirurgia. Chamou minha atenção a amabilidade das pessoas (pacientes e acompanhantes), tentando ajudar para que ficasse confortável, tanto no setor de radiologia quanto no laboratório. No dia da cirurgia, apresentei-me na Unidade Cirúrgica, conforme combinado. Após aguardar numa sala de espera, passaram à mim e à minha irmã para outro recinto mais reservado; conduziram-nos ao vestiário para que me paramentasse, e a técnica pediu à minha irmã que me acompanhasse ao banheiro. Depois ficamos aguardando em uma sala muito bem equipada: TV com tela grande, sofás enormes, revistas, brinquedos para crianças. $\mathrm{O}$ anestesista e um assistente do Dr. X vieram e se apresentaram bastante amáveis. Pouco depois fui conduzida à sala de cirurgia, onde me ajudaram a deitar na mesa e iniciaram os procedimentos anestésicos. Acordei na sala de recuperação e imediatamente veio uma fisioterapeuta com um aparelho tipo tração com monitor e, para minha surpresa, já iniciou exercícios de flexão e extensão leves. Mais tarde, à noite, fui liberada para o quarto. Entre alguns cochilos e pedidos para ir à comadre, a enfermagem trazia, de tempos em tempos, medicação como antibiótico e analgésicos, além de anticoagulante para o acesso venoso. No dia seguinte e, após alguma demora, alguns procedimentos de rotina da enfermagem: banho de leito, higiene oral, comadre, troca de medicação por via EV e, mais tarde, fisioterapia. Nunca me questionaram como eu estava me sentindo. O assistente do Dr. X passou para me ver e dizer que tudo havia transcorrido bem e havia sido necessário fazer um enxerto (retirado do osso ilíaco D). Estava saindo para o feriado de Natal e Dr. X entraria em contato mais tarde. Fiquei aliviada, pois essa havia sido uma preocupação ao fazer a cirurgia, justo na véspera do feriadão de Natal; contudo, Dr. X assegurou-me que estaria disponível, junto com sua equipe (ou foi o que eu quis entender). Estava previsto ficar no hospital por mais ou menos quatro dias. Dr. $\mathrm{X}$ telefonou um pouco mais tarde (o que estranhei, pois pensei 
que viria pessoalmente), mais ou menos repetindo o que seu assistente havia falado, perguntou se estava bem e sem me dar muita chance, desligou. Em todos os turnos, uma enfermeira se apresentava, com uma prancheta nas mãos, dizendo estar disponível para o que fosse necessário, mantendo certa distância, posicionando-se sempre aos pés da cama; poucas perguntaram como eu estava e ninguém se aproximou para examinar a região cirúrgica, o dreno de porto-vac ou o acesso endovenoso... À noite, novamente, só cochilos, e, pela madrugada, comecei a apresentar enjôos, para os quais me aplicaram medicação. As 5 hs da manhã vomitei e continuei desagradavelmente enjoada. O plantão (estávamos no dia 25 de dezembro) iniciou devagar: meu banho atrasaria. Indaguei se não podia sentar e fazer a higiene no banheiro e responderam: - "Não tem nada escrito a respeito". Um pouco antes das $10 \mathrm{hs}$, entrou um rapazinho que se apresentou como assistente do Dr. X. Falei de meus enjôos, não falou nada. Então, disse que eu já podia ir para casa, que iria encaminhar meus papéis de alta. -"Mas já? Dr. X falou em quatro dias, hoje à tarde tem fisioterapia e estou achando minha perna edemaciada!" Respondeu: - "Está tudo bem, tem que ter paciência, paciência, não vai querer ficar aqui só para fazer fisioterapia, não é?" Escreveu alguns receituários, todos de analgésicos, e que eu deveria retornar na $2^{\mathrm{a}}$ feira para revisão, e saiu. Pronta para sair, a técnica de enfermagem trouxe uma cadeira de rodas, pois o assistente havia solicitado um RX. Recusei a cadeira, que não tinha suporte para a perna, já que no dia anterior, ao descer do $8^{\circ}$ andar para o térreo, havia feito o trajeto segurando a perna para o alto. Trouxeram uma maca e fui conduzida com todos os meus pertences, sendo que do RX poderia ir embora. No setor de RX, estranharam a conduta, a técnica de enfermagem falou que após poderiam me passar para a cadeira, pois estava de alta e, assim, foi embora. Contudo, após algumas reclamações e um tempo de espera, realizaram o RX e, da mesa, me ajudaram a sentar na cadeira de rodas e fui liberada. Minha irmã foi ver onde era a saída daquele setor e providenciar um táxi. Conduziu-me até ele, voltando para pegar meus pertences e as muletas que havia trazido. Fiquei bem apreensiva ao tentar passar da cadeira para o táxi e constatar minha quase impossibilidade de lidar com as muletas (no entanto, antes da cirurgia eu as manejava muito bem). Em nenhum momento a enfermeira da unidade apareceu para verificar a alta e saí sem qualquer documentação.

\section{Cenário 5 - A volta para casa}

Ao descer do táxi e tentar cruzar o portão, entrei em pânico: praticamente não conseguia mover minha perna direita, e a esquerda, a operada, estava proibida de firmá-la no chão. Não poderia entrar pela frente, pois os degraus eram muito altos. Assim, fui manobrando as muletas, precariamente, com muita dificuldade e dor, até os fundos da casa, onde os degraus eram mais baixos. Não sei como consegui, pois eram cerca de 20 metros e, por vezes, quase cai. A subida dos degraus foi uma tragédia, acabei firmando um pouco com a perna esquerda, parecendo-me mais firme do que a direita. Novamente apelei para a cadeira do computador, no entanto, a movimentação estava muito difícil; não conseguia impulsionar a perna direita para empurrá-la. Sentia algo errado: faltava firmeza e sentia dor na região do quadril.

Contatamos um serviço de "homecare", o que não foi fácil, já que estávamos em pleno feriadão de Natal. Eu necessitava auxílio para locomover-me com a cadeira improvisada, principalmente para o banheiro, e ajuda para o banho. Por sorte, no dia seguinte, conseguimos encontrar uma casa que alugava cadeira de rodas; praticamente tudo se encontrava fechado em função do feriado. Eu me senti miserável nesse dia, como um pacote de lixo que havia sido descartado! Contratei um casal para levar meus cães a passear, o qual gentilmente se ofereceu para buscar a cadeira, entre tantos outros favores que me prestaram! Outra amiga conseguiu-me uma comadre.

Continuava com os enjoos, não conseguia dormir e tinha uma cefaléia horrível. Minha perna (no local da cirurgia) e tornozelo apresentavam-se edemaciados e quentes. Iniciamos a tentativa de contatar o Dr. X, e aí nos demos conta que não havia nos deixado qualquer telefone para contato! Consegui uma acompanhante que se ofereceu para ficar comigo durante a noite, o que foi um alívio, pois, além de dispendioso, o serviço de "homecare" não me pareceu muito eficiente. A moça que se ofereceu, e que já a conhecia, foi de muita ajuda, sentia-me mais à vontade, era bastante discreta $\mathrm{e}$ solícita. Através do hospital, consegui contatar, após um dia de tentativas, com um dos assistentes do Dr. X, que estava de plantão. Esse lhe passou o recado e ele, finalmente, telefonou da praia para saber o que estava acontecendo. Orientou colocar gelo, ficou um pouco irritado, pois deixamos claro que achávamos que a alta havia sido muito precoce, respondendo que havia sido devido ao "problema de ocorrência de infecção hospitalar". 
E que "não tinha culpa de eu ter sido atropelada". Iniciei, então, com gelo; os exercícios ficaram mais fáceis com a diminuição do edema. A minha dificuldade parecia ser no quadril direito, impedindo o auxílio das muletas.

\section{Cenário 6 - A relação médico-paciente}

Minha consulta de revisão estava marcada para as 14 hs do dia 28 de dezembro. Dr. X chegou atrasado e só me atendeu por volta de $15 \mathrm{~h} 20 \mathrm{~min}$. Conduzida para um dos boxes do ambulatório, uma técnica de enfermagem abriu os curativos e ainda aguardei por uns quinze minutos. Ao entrar, Dr. X perguntou como eu estava e respondi que a recuperação estava um pouco mais lenta do que esperava, em função das dificuldades que havia enfrentado ao voltar para casa. Imediatamente respondeu -“Não sei por que vocês (eu e minha irmã) estão sempre brigando comigo!" Respondi que não estávamos brigando, apenas tentando explicar que não tínhamos condições estruturais para minha volta. Dr. X replicou: - "Nós não temos controle sobre como os pacientes vão fazer em casa".

- "Acontece que eu quase caí, continuo sem poder firmar a perna direita e não sei por quê!" Bastante irritado falou: - "Eu falei que não era para firmar a perna esquerda, assim estraga todo o meu trabalho!" - "Justamente isso que eu queria lhe explicar, pois apesar de sua competência e habilidade técnica, quase ocorreu um desastre, por falta de condições". Acrescentei que morava sozinha, numa casa com escadas. - "Você não tem amigos, vizinhos?" - "Dr. X, estávamos em feriados e comemorações de final de ano; a maioria das pessoas estava fora!" Gostaria de ter acrescentado: - "Assim como o senhor". Olhou o local da cirurgia e do enxerto, dizendo que estava tudo ótimo. Encaminhou-me para o RX e, apesar de insistir em falar da outra perna, não me deu atenção. O RX confirmou que a cirurgia havia sido um sucesso. Indaguei se poderíamos tentar fisioterapia domiciliar através de meu convênio de saúde, o que achou difícil e perguntou: - "Mas já não estás fazendo fisioterapia? Você havia me dito que fazia fisioterapia por vários anos!" - "Mas Doutor, eu fazia fisioterapia para outros problemas!" Surpreendeu-me muito a pergunta do Dr. $X$, pois naquele momento tratava-se de uma nova situação, com um novo diagnóstico, portanto necessitaria de uma nova requisição para outro tipo de fisioterapia e de autorização por parte da seguradora de saúde. Alguns médicos, inclusive, costumam fornecer informações por escrito à fisio- terapeuta, sobre os exercícios a serem reforçados. Dispensada, orientou-me a ir à sua clinica, na semana seguinte, para retirada dos pontos e novo RX. Antes de sair, pedi para ir ao banheiro e fui informada que o mesmo se localizava na saída. As pessoas (pacientes, familiares e outras), bastante solícitas, prontificaram-se a abrir as portas para eu passar e, já do lado de fora, fomos informadas que o banheiro para cadeirantes localizava-se no $2^{\circ}$ pavimento!

\section{Cenário 7 - A recuperação}

Iniciei a fisioterapia em casa, pois continuava com problemas de locomoção com a perna direita, e havia a escada. Não consegui a autorização pelo convênio, portanto, estava fazendo a fisioterapia de forma particular. Alguns problemas estavam melhorando, como a insônia, os enjoos, e, consequentemente, passei a me alimentar melhor, assim como o intestino voltou a funcionar. Amigas e vizinhas me ajudaram fazendo compras, auxiliando com a higiene, até pintando cabelo e trazendo comida! Minha irmã, contudo, foi a principal cuidadora, em quase todos os momentos. $\mathrm{Na}$ semana seguinte, retirei os pontos e, finalmente, Dr. X escutou minha queixa quanto ao problema com a perna direita. Pediu RX do joelho, várias posições e, além deste, da coluna e quadril direito. Nada constatou, além das lesões que já possuía na coluna, e do que mostrava o quadril, em função da retirada do enxerto. Nada parecia justificar a dor e a incapacidade para movimentar-me com o auxílio das muletas. Intrigada, assim como a fisioterapeuta que me atendia, pensamos em algum traumatismo de partes moles. Sem melhoras, dias depois marquei consulta com o Reumatologista que me tratava há alguns anos e no qual depunha muita confiança. Expliquei a ele minha situação. Ele me examinou e constatou uma bursite na altura do trocanter direito e uma contratura severa. Receitou-me antiinflamatório, analgesia específica e recomendou alguns exercícios, além de gelo no local da bursite. Ficamos conjeturando e a explicação mais plausível era a que eu já suspeitava: o esforço realizado no dia da alta hospitalar ao chegar a casa, equilibrando-me precariamente com as muletas e subir a escada.

Para uma pessoa ativa, a imobilidade é um exercício de paciência e, no meu caso, provavelmente, levaria alguns meses para que, esperançosamente, recuperasse os movimentos. Portanto, era tudo comigo: paciência, perseverança e confiança! Já não estava tão dependente, e alguns favores, 
que amigas e vizinhas haviam se disponibilizado, não eram mais tão necessários. A ajuda de todas essas pessoas, além de outras com as quais convivi, mesmo que de forma muito superficial, foi indescritível e me deixaram bastante comovida.

\section{OS COMPORTAMENTOS E ATITUDES DE CUIDADO OU HUMANIZAÇÃO}

A experiência vivida foi analisada sob a perspectiva interpretativa, conforme já referido no início do texto e, através da mesma, foi possível destacar alguns pontos interessantes, principalmente considerando os modos de ser, expressos nas atitudes e comportamentos evidenciados pelos cuidadores, tanto leigos quanto (e principalmente) os profissionais de cuidado.

No que tange à humanização, termo considerado de difícil conceituação, devido ao seu caráter de subjetividade, complexidade e multidimensionalidade, na saúde implica "[...] muito mais do que qualidade clínica dos profissionais, exige qualidade de comportamento." 9:140 Falhas são relatadas no que se refere à proposta de uma política de humanização da assistência ${ }^{6} \mathrm{e}$, na verdade, segundo algumas opiniões, "[...] encontra-se longe de constituir-se em realidade." 10:38 Ademais, é importante ressaltar que a humanização nos serviços de saúde deveria objetivar a sensibilização de todos os protagonistas envolvidos, destacando os profissionais de saúde, ou seja, enfermeiros, nutricionistas, fisioterapeutas e, principalmente, médicos. ${ }^{11} \mathrm{O}$ cuidado é considerado como sendo o que distingue o ser como humano ou seja, o ato de cuidar humaniza o ser e implica em compromisso e responsabilidade. São mencionados como atitudes e comportamentos de cuidado, entre uma infinidade: a preocupação com o outro, o respeito, a consideração, a confiança, a compaixão, a solidariedade, a solicitude. Envolvem ética e estética, além da técnica e todos os seres são capazes de desenvolver esses comportamentos e atitudes, desde que sensibilizados e que se acione a consciência de cuidado. ${ }^{2}$

Em relação aos comportamentos e atitudes de cuidado ou humanização, foi possível destacar alguns, em cada um dos cenários e que, em alguns momentos, caracterizaram-se pelo oposto, ou seja, como comportamentos e atitudes de não cuidado ou desumanização.

No cenário 1, por exemplo, destaca-se a preocupação e a ajuda de pessoas leigas que prestaram socorro, no sentido de ajudar para que a acidentada ficasse o mais confortável possível, cuidando para não causar nenhum dano maior. O serviço de atendimento, pelos técnicos da ambulância, não se mostrou mais do que normal, fazendo o que é esperado. Cumpre ressaltar a falta de aparelhagem básica, como esfignomanômetro. No cenário 2, infelizmente, também nada foi digno de registro. Todos exercendo suas funções, sem grande envolvimento; destaque para a situação de indiferença e falta de compromisso em atender uma necessidade básica da paciente ao solicitar a comadre. A atitude da enfermeira no setor modificou, tornando-se solícita, ao constatar que a paciente era uma colega de profissão e, daí em diante, apoiou-a, fazendo-lhe companhia até sua saída. Providenciou ajuda de outras colegas da enfermagem para o translado até o táxi. Nesse cenário (3), foi merecedor de nota o comportamento e atitude do motorista de táxi que, além de solicitude, solidariedade, mostrou preocupação e ofereceu ajuda, carregando a paciente.

Chamou a atenção a superespecialização que ocorre em alguns serviços da medicina, em relação às especialidades, tais como o da clínica, as quais fragmentam toda a atenção aos pacientes, tratando-os por partes: joelho, ombro, quadril, etc. Por outro lado, observou-se, nos vários serviços de saúde utilizados, a falta de planejamento no que concerne à estrutura física para pacientes incapacitados (as escadas na clínica, os espaços exíguos e a localização do banheiro no hospital, por exemplo). No cenário 4 , fica evidente a preocupação dos profissionais em realizar suas tarefas com ênfase nos procedimentos técnicos. Apesar de as enfermeiras declararem sua disponibilidade, mantinham distância e não evidenciavam qualquer preocupação em avaliar as condições físicas, tanto em termos de conforto quanto de segurança. Nenhuma se mostrou presente em qualquer outra circunstância. A situação de alta foi incomum, mostrando total falta de compromisso e responsabilidade para com a paciente. Os profissionais da medicina mostraram indiferença às necessidades da paciente, desatenção e, inclusive, grosseria. Esses comportamentos e atitudes se repetiram no cenário 4 . Nesse, destaque para a solidariedade, atenção e disponibilidade de pessoas conhecidas, amigos e parentes.

No cenário 5, a relação médico-paciente mostrou-se um pouco difícil. Autoritarismo, intolerância a comentários que parecem ter sido encarados como crítica negativa. A preocupação do médico ficou focada no seu trabalho, sem tomar em consi- 
deração as necessidades e condições da paciente. Por outro lado, as atitudes e comportamentos do médico causaram insegurança e descrédito quanto a sua competência. O cenário 6 só confirmou algumas atitudes e comportamentos positivos por parte de pessoas, não cuidadoras formais.

Recomenda-se que o processo de humanização deve concretizar-se no viés de uma ação coletiva, abrangendo não só os sujeitos, mas o espaço em que se encontram, ou seja, a estruturação do ambiente, de forma que tanto cuidadores quanto seres a serem cuidados beneficiem-se, atendendo suas necessidades de segurança e conforto. A humanização ou o cuidado deve centrar-se, prioritariamente, no ser a ser cuidado, mas só se viabiliza no momento em que os profissionais conscientizem-se disso, a partir de seu próprio cuidado. Assim, concorda-se com o afirmado de que o profissional venha a ser sujeito e agente de mudança por meio de práticas reflexivas, tornando-se consciente e capaz de intervir na realidade e, consequentemente, transformando-a. ${ }^{3}$

Considerando o exposto, propõe-se refletir as estratégias e atividades previstas em relação à política de humanização da saúde. ${ }^{10}$ Algumas recomendações são feitas, ${ }^{11}$ no sentido de trabalhar essa questão, em termos de currículo. No entanto, parece necessário inserir, nas sensibilizações e "treinamentos", os profissionais da prática, principalmente da área da medicina e enfermagem, já que seus comportamentos e atitudes são mencionados como de não cuidado ou desumanizantes. ${ }^{12-13}$

\section{CONSIDERAÇÕES FINAIS}

Tomando-se a narrativa como um todo, constatou-se que as atitudes e comportamentos de cuidar, ou a humanização por parte dos profissionais de saúde, principalmente da área médica e da enfermagem, ficaram a desejar. Foi possível identificar competência em termos de habilidade técnica, porém, mostraram, quase sem exceção, distância, grosseria e, por vezes, indiferença. O paciente não é o foco de atenção, e sim, os procedimentos, as tarefas, a habilidade técnica. Essa constatação mostra a resistência das instituições e dos profissionais de saúde em abraçar, de fato, as novas propostas paradigmáticas e as recomendações no que tange à política de humanização. Já por parte de pessoas leigas, não cuidadoras formais, foi possível evidenciar, em várias circunstâncias, atitudes e comportamentos, tais como: solidariedade, preocupação, oferecimento de ajuda, disponibilidade, solicitude. Frente a essa constatação é que procede a pergunta: "quem cuida, afinal?" Essa questão, na verdade, responde o que se constatou acima, ou seja, o cuidado ou humanização encontram-se ausentes na expressão dos profissionais de saúde, preocupados apenas em desenvolver tarefas, em executar procedimentos, e que seriam os mais esperados a evidenciá-los, já que são "supostamente" preparados formalmente para cuidar e, "supostamente", de forma integral.

A experiência mostrou-se, portanto, bastante decepcionante, principalmente ao considerar-se toda a ênfase dada, mais recentemente, em prol de uma humanização da assistência. Por outro lado, espera-se contribuir com o presente relato em uma reflexão sobre esta temática, assim como no ensino que ora vem privilegiando o cuidado como "essência da enfermagem".

\section{REFERÊNCIAS}

1. Cardoso MHCA, Camargo JrKR, Llerena JrJC. A epistemologia narrativa e o exercício clínico do diagnóstico. Ciênc Saúde Coletiva. 2002 Set-Dez; 7(3):555-69.

2. Waldow VR. Atualização do cuidar. Aquichan. 2008 Abr; 8(1):85-96.

3. Backes DS, Lunardi WLF, Lunardi VL. A construção de um processo interdisciplinar de humanização à luz de Freire.Texto Contexto Enferm. 2005 Jul-Set; 14(3):427-34.

4. Waldow VR, Borges RF. Humanizar e cuidar: relações e significados. Acta Paul Enferm. 2011 MaiJun; 4(3):444-18.

5. Cardoso CF. Narrativa, sentido, história. Campinas (SP): Papirus; 1997.

6. Ricouer P. Tempo e narrativa. Campinas (SP): Papirus; 1994.

7. Benner P. From novice to expert: excellence and power in clinical nursing practice. Menlo Park (CA): Addison-Wesley; 1984.

8. Benner P, Tanner CA, Chesla CA. Expertise in nursing practice: caring, clinical judgement, and ethics. New York (US): Springer Publishing Company,Inc.; 1996.

9. Simões ALA, Rodrigues FR, Tavares DMS, Leiner RR. Humanização na saúde: enfoque na atenção primária. Texto Contexto Enferm. 2007 Jul-Set; 16(3):439-44.

10. Ministério da Saúde (BR). Política Nacional de Humanização: Humaniza SUS: documento base. Brasília (DF): Núcleo Técnico da Política Nacional de Humanização, 2006.

11. Reis AOA, Marazina IV, Gallo PR. A humanização na saúde como instância libertadora. Saúde Soc. 2004 Set-Dez; 13(3):36-43. 
12. Caprara A, Franco ALS. A relação paciente-médico: para uma humanização da prática médica. Cadernos de Saúde Pública. 1999 Jul-Set; 15(3):647-54.
13. Wolff LR, Waldow VR. Violência consentida: mulheres em trabalho de parto e parto. Saúde e Sociedade. 2008 Jul-Set; 17(3):138-51. 